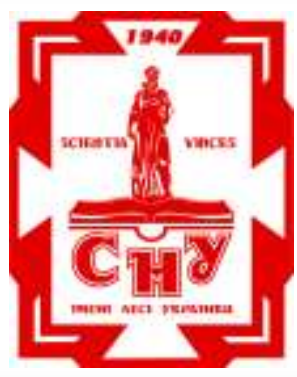

Науковий вісник Східноєвропейського національного університету

імені Лесі Украӥнки

Розділ І. Ботаніка

Серія: Біологічні науки, 2020, 2 (390)

УДК 581.4:581

$10.29038 / 2617-4723-2020-390-2-3-7$

\title{
Морфологія квітки та фенологія Cyrtanthus elatus (Jacq.) Traub (Amaryllidaceae J.St.-Hil.) у культурі
}

\section{Оксана Фіщук}

Волинський національний університет імені Лесі Українки, Луцьк, Україна Адреса для листування: dracaenaok@ukr.net

Резюме. Cyrtanthus elatus - ендемік флори Південної Африки, південних прибережних гір від півночі міста Моссел-Бей у Західній Капській провінції до міста Гумансдорпа у Східній Капській провінції. Він трапляється в колоніях на суглинистих, кислих грунтах на вологих схилах, що виходять на південь, при повному сонці чи легкій тіні. Цвітіння посилюється в період кущових пожеж. Рослини C. elatus швидко розвиваються влітку, вічнозелені, нові листки з'являються незабаром після пожеж та цвітіння, що проходять у будь-який час з кінця весни до середини осені.

Він включає чіткі форми росту, деякі з них характеризуються швидким розмноженням цибулин і нестабільним цвітінням, принаймні під час вирощування, а інші цвітуть рясно і менш схильні до вегетативного розмноження. У відділку тропічних і субтропічних рослин Волинського національного університету імені Лесі Українки перші колекці C. elatus (Amaryllidaceae) з'явилися у 2008 році. Фенологічні спостереження показали, що рослини C. elatus вступають до генеративного періоду у віці 23 років. Досліджені морфологічні особливості квіток і плодів C. elatus в умовах культури. Коли рослини досягли генеративного онтогенетичного стану, проводили облік термінів і тривалості цвітіння. Під час цвітіння рослин проводили штучне запилення, для якісного утворення плодів. Модельні рослини цвітуть 16-20 днів та мають у суцвітті 4-5 квіток, кожна 3 них у середньому цвіте 3-4 дні. Проведено фенологічні спостереження за цвітінням квітки та дозріванням плодів. Вивчено морфологію квіток, зокрема гінецею та андроцею. Пилок зберігає $100 \%$ життєздатність та міститься у пиляках у великій кількості. Плід ягодоподібна коробочка еліпсоїдної форми, довжиною 37-39 мм, насінини 7-8 мм завдовжки, плоскі, чорного кольору з крилатим виростом. Морфологічні особливості квітки, велика кількість пилку $є$ пристосуванням до комах запилювачів.

Ключові слова: Cyrtanthus elatus, фенологія, морфологія, запилення, квітка, плід

\section{Flower morphology and phenology of Cyrtanthus elatus (Jacq.) Traub (Amaryllidaceae J.St.-Hil.) in culture}

\section{Oksana Fishchuk}

Lesya Ukrainka Volyn European National University Lutsk, Ukraine Correspondence: dracaenaok@ukr.net

Abstract. Cyrtanthus elatus is an endemic in the flora of South Africa, from the southern coastal mountains from the northern city Mossel Bay in the Western Cape to the city of Humansdorp in the Eastern Cape. It occurs in colonies on loamy, acidic soils on moist slopes facing south, in full sun or light shade. Flowering intensifies 
during bush fires. C. elatus plants grow rapidly in summer and are evergreen, new leaves appear unprotected after the fire and flowering, which takes place at any time from late spring to mid-autumn.

It includes distinct forms of growth, some of which are characterized by rapid reproduction of bulbs and unstable flowering, at least during cultivation, while others bloom profusely, and are less likely to vegetative propagation. In the Department of Tropical and Subtropical Plants at agrobiostation of the Lesya Ukrainka Volyn National University, the first collections of $C$. elatus (Amaryllidaceae) appeared at the agricultural station in 2008. Phenological observations have shown that $C$. elatus plants enter the general period at the age of 2-3 years. The morphological features of flowers and fruits of $C$. elatus in culture were studied. When plants reach a generative ontogenetic state, we kept records of timing and duration of flowering. Plants were artificially pollinated during flowering for quality fruit formation. Model plants bloom for 16-20 days and have 4-5 flowers in the inflorescence, each of which blooms on average for 3-4 days. Phenological observations of flower blooming and fruit ripening were carried out. The morphological feature, especially gynoecium and androecium, have been studied. Pollen retains $100 \%$ viability and contained in pollen in large quantities. The fruit is a fleshy capsule ellipsoidal shape, 37-39 mm long, seeds 7-8 mm long, flat, black with a winged growth. Morphological features of the flower, a lot of pollen are an adaptation to buzz-pollination.

Keywords: Cyrtanthus elatus, phenology, morphology, pollination, flower, fruits.

\section{ВСТУП}

Родина Amaryllidaceae s. l. представлена великою кількістю декоративних рослин, 3 великими та яскравими квітками. Більшість представників цієї родини зростає у тропічній і субтропічній зонах. Рід Cyrtanthus (Amaryllidaceae) налічує близько 55 видів цибулинних рослин, корінних жителів південної та тропічної Східної Африки, які переважно зустрічаються в Південно-Східній Капській провінції. Там зафіксовано близько 25 видів, 7 із південної Капської провінції та 10 із Трансваальської провінцій [10]. Найвища концентрація видів переважає там, де цілий рік опади (Південно-Східна Капська провінція). Квітки багатьох видів звисають із вершин схилів. Деякі види, зокрема й C. elatus, мають прямостоячі квіти та широку трубку оцвітини, яка звужується і є коротшою за вільні листочки оцвітини. У більшості видів Cyrtanthus квіткова трубка довша за вільні листочки оцвітини і має циліндричну форму. Представники роду Cyrtanthus мають квітки різних кольорів: жовті, кремові, рожеві, червоні та білий. Квітки C. elatus червоні. Рід належить до родини Amaryllidaceae J. St.-Hil., підродини Amaryllidoideae, триби Cyrtantheae i налічує близько 56 видів $[2,12]$.

П.Т. Трауб у 1963 році [13] розмістив рід Cyrtanthus у трибу Cyrtantheae, розташування роду було підтримане й сучасними авторами [7], тоді як інші систематики помістили рід Cyrtanthus у трибу Haemantheae [9], хоча Cyrtantheae як монотипова триба на основі вивчення морфології цибулин та числа хромосом була виділена Р.М.Т. Дальгреном і співавторами [3]. Комбіновані послідовності $\mathrm{rbcL}$ i пластид trnL-F [8] вказують на положення Cyrtanthus як сестринської гілки для решти амарилісових після розгалуження триби
Amaryllideae. Проте за послідовністю $\mathrm{ndhF}$ пластид [11] Cyrtanthus розмістився сестринською кладою до тієї, що включає триби Calostemmateae та Haemantheae. Рід демонструє високий рівень флористичного й морфологічного різноманіття, що не має аналогів у будь-якому іншому роді родини.

За допомогою квіткових типів [5] можна зробити висновки про характерних запилювачів, простежуємо еволюцію добору флористичних ознак та оцінюємо таксономічні наслідки для роду, оскільки довга квіткова трубка й септальні нектарники $€$ пристосуванням до комахозапилення. В умовах культури, при відсутності властивих для цієї рослини запилювачів, необхідно застосовувати методику запилювання представників роду Cyrtanthus для отримання якісного насіння, яке проростатиме й утворюватиме організм рослини в умовах успішної інтродукції, оскільки в природних умовах ендемік C. elatus запилюється метеликом Meneris tulbaghia, якого приваблює яскравий червоний колір квітки та зручна квіткова трубка [6]. Метою нашої роботи було виявлення морфологічних особливостей квіток i плодів, проведення фенологічних спостережень та розробка схеми запилення C. elatus

\section{ОБ’ЄКТИ I МЕТОДИ}

На агростанції Волинського національного університету імені Лесі Українки до колекції тропічних i субтропічних рослин належить C. elatus - ендемік флори Південної Африки. Перші особини рослин були отримані 3 приватної колекції у 2008 році, а наймолодші екземпляри 3 насіння репродукції були отримані у 2013 році. C. elatus вирощують у грунтосуміші для сукулентних цвітучих рослин. Фенологічні спостереження здійсню- 
вали кожні 2-3 доби, а за процесом цвітіння слідкували тричі на день, спостереження за етапами цвітіння квітки проводили не менше двох разів на добу. Окремі органи рослини, зокрема квітки та листки, досліджували 3 використанням оптичного мікроскопа марки LABOVAL 4 фірми CARL ZEISS (Jena) та бінокуляру марки МБС-10, мікрофотографії отримані за допомогою камери марки CANON 1000 D. Життєздатність пилку аналізували за ацетокарміновим методом [1]. Аналізували пилок через 48 годин після зацвітання квітки. Досліджували такі морфологічні ознаки у C elatus, як довжина оцвітини, ширина листочків оцвітини, довжини зовнішніх i внутрішніх тичинок та діаметру тичинкових ниток, довжини та діаметру пиляків, висота i діаметр зав’язі, довжина і діаметр стовпчика.

\section{РЕЗУЛЬТАТИ ДОСЛІДЖЕНЬ}

C. elatus - декоративна тропічна рослина, привабливі квіти якої безперечно доповнять будь-який інтер'єр (рис. 1). Однак, якщо квіти розвиваються в умовах недостатнього освітлення в інтер'єрі, вони можуть зменшуватись у розмірах та бути блідого, не дуже насиченого кольору.

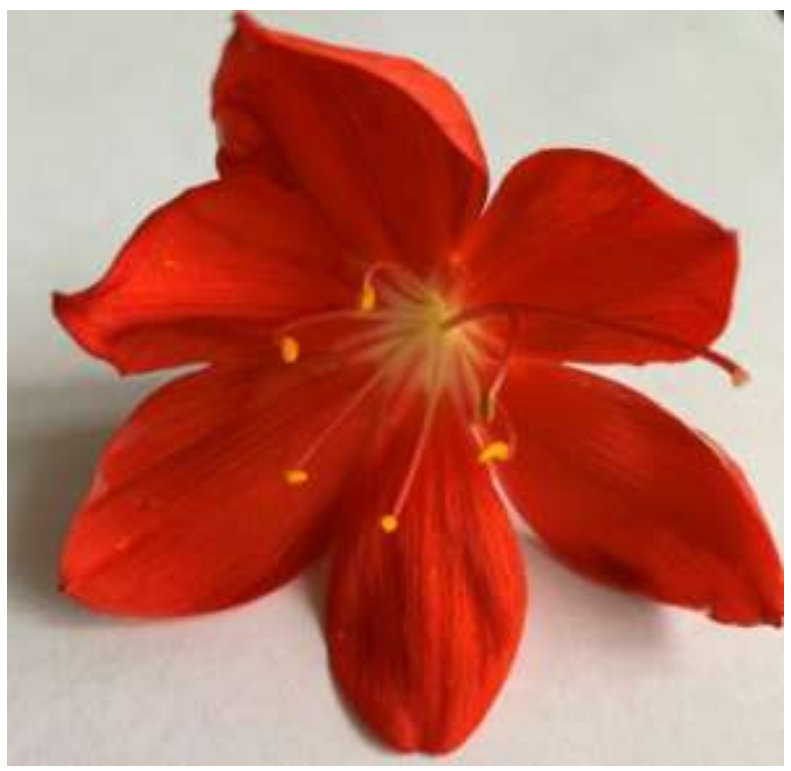

Рис. 1. Загальний вигляд квітки Cyrtanthus elatus (Jacq.) Traub.

Рослини вічнозелені, гарно розвиваються у літній період. У середньому висота рослини 410-640 мм. Листки розвиваються швидко, мають широко ременеподібну форму, довжиною 210-340 мм, 18-32 мм завширшки, насичено-зеленого кольору iз заокругленими закінченнями. Суцвіття зонтик із 3-9 квіток, квітконіс прямостоячий 370-595 мм завдовжки, порожнистий, світло-зеленого кольору; приквітки 2 яйцеподібні, гофровані, квітконіжки прямостоячі 18-35 мм, світло-зелені. Квітки зигоморфні, широко лійкоподібні, насиченочервоні, без запаху, довжиною 90-120 мм; вільні листочки оцвітини яйцеподібні, вигнуті (рис. 2). Тичинкові нитки довжиною 70-72 мм, світло-червоного кольору, пиляки лінійні, довгасті. 4-5 мм, пилок жовтий. Зав'язь зеленого кольору, складається 3 трьох зрослих плодолистків 12-13 мм довжиною, містить в собі велику кількість насінних зачатків, стовпчик злегка зигоморфний, довжиною 90-110 мм, білого кольору у нижній частині та світлочервоного кольору зверху, приймочка головчаста (рис. 3), плід трилопатева ягодоподібна коробочка еліпсоїдної форми, довжиною 37 39 мм, насінини 7-8 мм завдовжки, плоскі, чорного кольору з крилатим виростом.

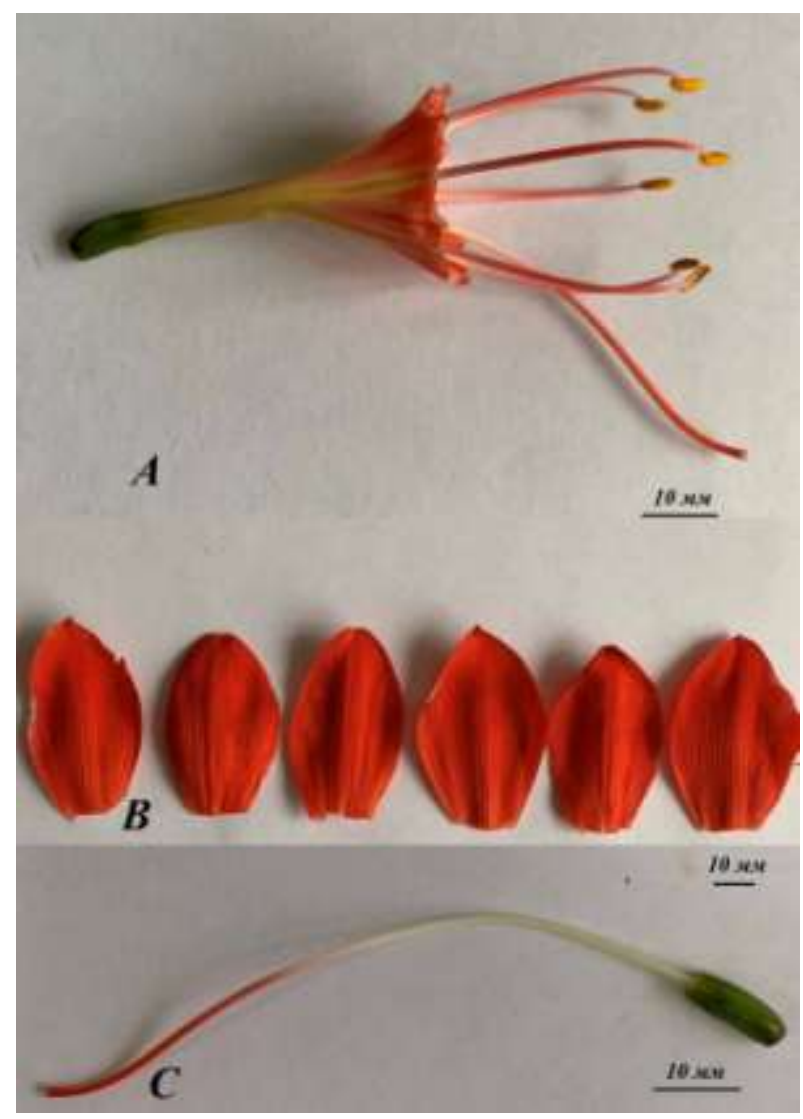

Рис. 2. $A$ - зовнішній вигляд квіткової трубки, стовпчика та андроцею Cyrtanthus elatus (Jacq.) Traub., B - вільні листочки оцвітини, $C$ - гінецей

C. elatus чудово підходить для вирощування у контейнерах 25-35 см, або в альпінаріях 3 помірним кліматом, потребує певного 
Морфологія квітки та фенологія Cyrtanthus elatus (Jacq.) Traub (Amaryllidaceae J.St.-Hil.) у культурі. розміщення, щоб отримувати ранкове сонце або яскраве світло протягом дня, а також необхідна добре дренована, багата гумусом, кисла грунтосуміш. Поливати циртантус потрібно кожні два тижні влітку та раз на місяць узимку. Рослини вразливі до вірусних захворювань, що поширюються борошнистими клопами та равликами [4].

Фенологічні спостереження. Ріст молодих бутонів C. elatus в умовах культури починався 3 4 жовтня до 22 жовтня 2018 року, загальний час цвітіння 19 днів. Квітки починали розкриватися

37 вересня і цвісти до 27 вересня 2019 року, загальна тривалість цвітіння 20 днів.

312 серпня до 28 серпня 2020 року період цвітіння C. elatus характеризувався швидким розвитком бутонів і тривав 16 днів, тому що температура повітря досягала $30^{\circ} \mathrm{C}$. Одна квітка в середньому цвіте 3-4 дні та має 4-5 квіток у суцвітті. Після цвітіння оцвітина не відпадає, а засихає. Пилок має майже $100 \%$ життєздатність як на четверту добу після розпускання квітки, так і після в'янення цілої оцвітини, та може використовуватись для запилення інших

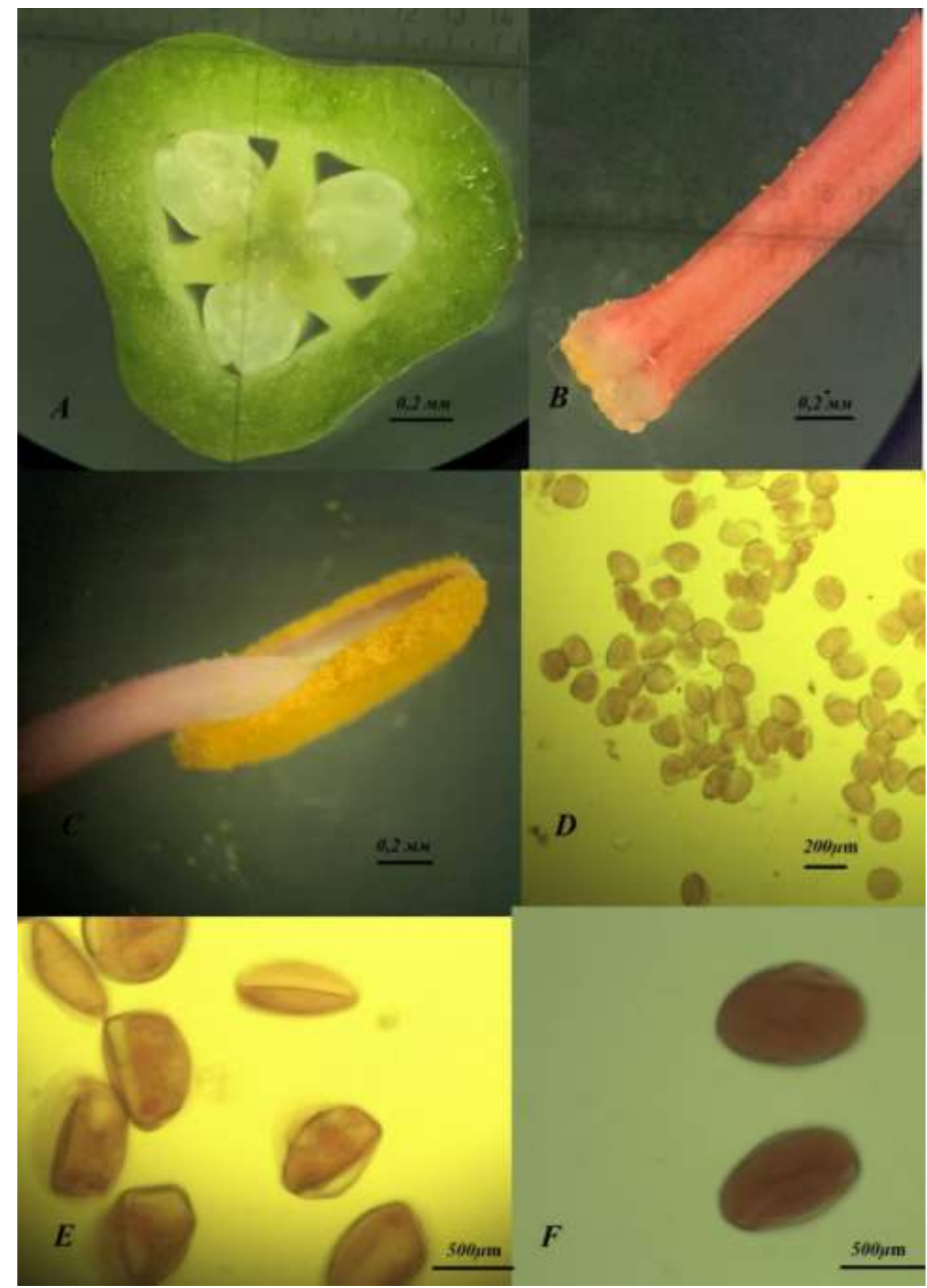

Рис. 3. $A$ - поздовжній розріз молодого плоду з насінними зачатками Cyrtanthus elatus (Jacq.) Traub., $B$ - приймочка, $C$ - загальний вигляд пиляка, $D-E$ - недозрілі пилкові зерна, $F$ - пилок на четверту добу ивітіння квітки. 
квіток, що розцвіли пізніше. Плоди зеленого кольору, дозрівають на 30-40 день. Насінини утворюються через 50-70 днів після початку цвітіння.

Температура та інтенсивність світла впливали на ріст та розвиток C. elatus. Суцвіття зароджувались при діапазоні температур (13$29^{\circ} \mathrm{C}$ ). Ініціація квітів була оптимальною від 21$29^{\circ} \mathrm{C}$, а розвиток рослини був оптимальним при $25^{\circ} \mathrm{C}$. Більші, яскравіші, оранжево-червоні квіти розвивались найкраще при температурі $22^{\circ} \mathrm{C}$. Затінення не впливало на швидкість утворення квітів, але призводило до високого рівня відмирання бутонів, особливо при температурі $24^{\circ} \mathrm{C}$. Суцвіття не 3'являлися при частковому затіненні. Квітконоси були найдовшими при $22-26^{\circ} \mathrm{C}$. Зміна температури від $18^{\circ} \mathrm{C}$ до $26^{\circ} \mathrm{C}$ та висока інтенсивність світла призвели до максимального розвитку коренів, пагонів та суцвіть.

Для вдалого запилення та якісного отримання плодів C. elatus було відібрано пилок із квіток, які вже перецвіли, і запилено квітки, які тільки починали цвісти, умови цвітіння та органи квітки не були порушені. Приймочку рясно запилювали, переносили пилок пензликом.

\section{ВИСНОВКИ}

Дослідження морфологічних особливостей квітки, фенології цвітіння C. elatus, високо декоративного ендеміка Південної Африки дало можливість оцінити вплив температури та яскравості світла на формування й ріст бутонів, розвиток квітки та плоду. Досліджений вид схожий за морфологією квітки до інших представників 3 родини Amaryllidaceae s.l. Ягодоподібні коробочки, що розриваються зсередини, $є$ характерною ознакою родини. Велика кількість насінних зачатків у зав'язі, наявність септальних нектарників, висока фертильність пилку та його кількість свідчать про адаптацію їх до комахозапилення. В умовах закриритого грунту запилення С. elatus проходить штучно із втручанням людини для якісного відтворення наступних поколінь.

Для вивчення різноманітності морфолог-гічних ступенів будови квітки в родині Amaryllidaceae J.St.-Hil. потрібно досліджувати не лише зовнішні ознаки, а й внутрішні, такі як мікроморфологія квітки, будова септальних нектарників, як результат адаптації до запилення та подальшого використання нових ознак у систематиці родини.

\section{ЛITЕРАТУРА}

1. Pausheva, Z. P. Praktikum po tsitologii rasteniy. [Workshop on cytology plants.]. Agropromizdat, Moskva, 1988, 271 s. (in Russian).

2. Chase, M. W.; Christenhusz, M.J.M.; Fay, M. F.; Byng, J. W., Judd, W. S., Soltis, D. E., Mabberley, D. J., Sennikov, A. N.; Soltis, P. S., Stevens, P. F. The angiosperm phylogeny group. An update of the angiosperm phylogeny group classification for the orders and families of flowering plants APG IV. Botanical Journal of the Linnean Society 2016, 181, pp 1-20. DOI:10.1111/boj.12385

3. Dahlgren, R.M.T.; Clifford, H. T.; Yeo, P. F. The families of the monocotyledons. Springer-Verlag, Berlin, Germany, 1985, 520 p. URL: https://doi.org/10.1111/j.1756-1051.1987.tb00937.x

4. Duncan, G.; Jeppe, B.; Voigt, L. The Amaryllidaceae of southern Africa. Hatfield (ZA), Umdaus Press, 2016, 709 p.

5. Goldblatt, P.; Manning, J. C. Radiation of pollination systems in the Iridaceae of sub-Saharan Africa Annals of Botany, 2006, 97, pp 317-344.

6. Johnson, S. D.; Bond, W. J. Red flowers and butterfly pollination in the fynbos of South Africa. In: Arianoutsou, M. \& Groves, R. (eds.): Plant-animal interactions in Mediterranean-type ecosystems; Dordrecht (NL): Kluwer Academic Publishers, 1994, pp 137-148. URL: https://doi.org/10.1007/978-94-0110908-6_13.

7. Meerow, A. W.; Snijman, D. A. Amaryllidaceae. In K. Kubitzki [ed.], Families and genera of vascular plants, Springer-Verlag, Berlin, Germany, 1998, 3, pp 83-110.

8. Meerow, A.W.; Fay, M. F.; Guy, C. L.; Li, Q. B; Zaman, F. Q.; Chase, M. W. Systematics of Amaryllidaceae based on cladistic analysis of plastid rbcL and trnL-F sequence data. American Journal of Botany, 1999, 86, pp 1325-1345.

9. Muller-Doblies, D.; Muller-Doblies, U. Tribes and subtribes and some species combinations in Amaryllidaceae J. St.-Hil. emend. R. Dahlgren \& al. 1985. Feddes Repertorium, 1996, 107 (5-6), pp 1-9.

10. Reid, C.; Dyer, R. A. A review of the southern African species of Cyrtanthus. American Plant Life Society, La Jolla, California, 1984.

11. Snijman, D. A. \& Meerow, A. W. Floral and macroecological evolution within Cyrtanthus (Amaryllidaceae): Inferences from combined analyses of plastid ndhF and nrDNA ITS sequences. South Afr. J. Bot., 2010, 76: 217238. URL: https://doi.org/ 10.1016/j.sajb.2009.10.010

12. Stevens, P. F. Angiosperm Phylogeny Website. URL: http://www.mobot.org /MOBOT/research/APweb 13. Traub, H. P. Genera of the Amaryllidaceae. American Plant Life Society, La Jolla, California, USA, 1963. 